\title{
THEORETICAL AND APPLIED APPROACHES TO QUALIFICATION OF CIVIL RELATIONS ON RENDERING SERVICES
}

\author{
Agnessa O. Inshakova \\ Volgograd State University, Volgograd, Russian Federation \\ Natalya V. Kagalnitskova \\ and Public Administration, Volgograd, Russian Federation
}

Volgograd Institute of Management - Branch of the Russian Presidential Academy of National Economy

Introduction: the article is devoted to studying separate issues of classification of civil legal relations, as relations on rendering services. For this purpose, the authors consider the features of the concept of "service", distinguished by the civil doctrine and used by the judicial practice. Using the methods of scientific knowledge, first of all, the method of system and comparative analysis, the authors identify the constitutive features of the concept of "service" by comparing the legal regime of the latter with the legal regime of "work". Results: it is established that the basis for the differentiation of relations on rendering services and performing works should be based on a set of features, but not the only one (the presence of a materialized result that can be delivered to the customer), as it is currently the case in law enforcement. Conclusions: the authors conclude that the contractual relations arising as a result of repair works should be qualified as a contractual relationship; the legal definition of the contract of paid services is unacceptable to all types of services, so the legal model of the contract of paid services should assume the existence of such obligations, where the professional service provider undertakes to achieve a specific intangible result, and the achievement of this result should be included in the subject of the legal relationship [1].

Key words: civil legal relationship, object of civil rights, "service", "work", "guarantee of result", instant consumability of service, paid services agreement, contract of work and labor.

Citation. Inshakova A.O., Kagalnitskova N.V. Theoretical and Applied Approaches to Qualification of Civil Relations on Rendering Services. Legal Concept, 2019, vol. 18, no. 2, pp. 90-93. (in Russian). DOI: https://doi.org/ 10.15688/lc.jvolsu.2019.2.14

\section{ТЕОРЕТИКО-ПРИКЛАДНЫЕ ПОДХОДЫ К КВАЛИФИКАЦИИ ГРАЖДАНСКИХ ОТНОШЕНИЙ ПО ОКАЗАНИЮ УСЛУГ}

\author{
Агнесса Олеговна Иншакова \\ Волгоградский государственный университет, г. Волгоград, Российская Федерация

\section{Наталья Владимировна Кагальницкова} \\ Волгоградский институт управления - филиал Российской академии народного хозяйства \\ и государственной службы при Президенте РФ, г. Волгоград, Российская Федерация
}

Введение: статья посвящена исследованию отдельных проблемных вопросов квалификации гражданских правоотношений как отношений по оказанию услуг. С этой целью авторы рассматривают признаки понятия «услуга», выделяемые цивилистической доктриной и используемые судебной практикой. С помощью методов научного познания, прежде всего метода системного и сравнительного анализа, автор выделяет конституирующие признаки понятия «услуга» путем сравнения правового режима последней с право- 
вым режимом «работы». Результаты: установлено, что в основу разграничения отношений по оказанию работ и выполнению услуг должна быть положена совокупность признаков, а не один (наличие овеществленного результата, который может быть передан заказчику), как это происходит в настоящее время в правоприменительной деятельности. Выводы: авторами сделаны выводы о том, что договорные отношения, возникающие в результате проведения ремонтных работ, должны квалифицироваться как отношения подрядного типа; легальное определение договора возмездного оказания услуг является неприемлемым ко всем видам услуг, поэтому нормативно-правовая модель договора возмездного оказания услуг должна предполагать существование и таких обязательств, гдепрофессиональный услугодатель берет на себя обязательство по достижению конкретного нематериального результата, причем достижение этого результата должно включаться в предмет обязательственного правоотношения [1].

Ключевые слова: гражданское правоотношение, объект гражданских прав, «услуга», «работа», «гарантированность результата», «моментальная потребляемость услуги», договор возмездного оказания услуг, договор подряда.

Цитирование. Иншакова А. О., Кагальницкова Н. В. Теоретико-прикладные подходы к квалификации гражданских отношений по оказанию услуг // Legal Concept = Правовая парадигма. $-2019 .-$ T. 18, № 2. C. 90-93. - DOI: https://doi.org/10.15688/lc.jvolsu.2019.2.14

\section{Введение}

В настоящее время в отечественном и зарубежном гражданском законодательстве появились новые виды договоров об оказании услуг, что обусловлено ростом доли услуг в имущественном обороте и, соответственно, вытеснением торговли материальными вещами. Вместе с тем исследователи отмечают, что, несмотря на достаточно широкую доктринальную проработанность понятия «услуга», последняя в российском праве имеет довольно размытые границы, обладает множеством смысловых оттенков, толкуется учеными и практиками по-разному, что негативно сказывается и на правоприменительной деятельности [1].

\section{Конституирующие признаки «услуги», выделяющие ее \\ в самостоятельный объект гражданского права}

Статья 128 Гражданского кодекса РФ закрепляет «услуги» в качестве объекта гражданских прав. Исходя из лексического толкования статьи, можно прийти к заключению, что «работы» (результат работы) и «услуги» составляют самостоятельную группу объектов гражданских прав наравне с имуществом [1]. Традиционное выявление признаков «услуги» происходит путем соотношения данной категории с наиболее близкой по правовой природе - «работы».

«Работы» принято дифференцировать с «услугами» по критерию предоставления ове- ществленного результата: подрядчик - лицо, выполняющее работу, - обязан не только осуществить предусмотренную соглашением сторон деятельность, но и сдать заказчику материальный результат [1]. Именно по этому критерию договор на осуществление ремонтных работ судебная практика довольно часто относит именно к договорам на оказание услуг. В частности, суд, рассматривая спор, вытекающий из договора ремонта судна, указал, что в данном случае должны применяться нормы гл. 39 ГК РФ, так как отношения сторон, вытекающие из обязательств подряда, всегда направлены на возникновение результата работ, который впоследствии должен расцениваться как самостоятельный объект гражданского права, понятие о котором закреплено в ст. 128 Гражданского кодекса Российской Федерации $[4 ; 5]$. В то же время в ряде случаев суды квалифицируют ремонтные работы как договор подряда (со ссылкой на ст. 703 ГК РФ), указывая, что в предмет договора подряда входит и «переработка (обработка)» вещи [3]. Также суды указывают, что целью договора подряда является не выполнение работы как таковой, а получение результата, который может быть передан заказчику. Получение подрядчиком определенного передаваемого (то есть материализованного, отделяемого от самой работы) результата позволяет отличить договор подряда от других договоров [2]. Полагаем, что сама конструкция «услуги» предполагает, что исполнитель выполняет только определенную деятельность и не обязан предоставлять какойлибо вещественный результат. Лицо, выпол- 
няющее работу, обязано произвести определенную работу и сдать результат заказчику (п. 1 ст. 702 ГК). При недостижении результата работа не считается исполненной. Заказчика в данном случае интересует только доброкачественный результат. Услуга же сводится к совершению ряда действий или осуществлению определенной деятельности (п. 1 ст. 770 ГК). Безусловно, при этом будет достигнут определенный результат, но не в форме вновь созданной или обработанной вещи. В данном случае правильнее будет говорить об эффекте услуги, который можно воспринимать на уровне чувств, но не получать как вещь. В то же время овеществленный результат может легко (быстро) исчезнуть, или более того, объект может вернуться к первоначальному состоянию, существовавшему до переработки или изготовления (например, услуги салонов красоты). В этом случае результат неустойчив, поэтому данное действие нельзя отнести к «работам». Указанные услуги в литературе именуются «так называемыми услугами», поскольку четкого термина для подобных «услуг-полуработ» цивилистика не выработала [6, с. 16]. В отличие от работ, в качестве признаков услуги можно также выделить «синхронность оказания и получения». Получение (принятие) услуги заказчиком и процесс ее оказания исполнителем, как правило, происходят одновременно. Принять услугу до того момента, пока не начат процесс ее оказания, и после того, как она оказана, невозможно. В отдельных случаях получение эффекта от услуги допустимо по истечении некоторого периода времени с момента завершения процесса ее оказания [1]. Именно данное качество «услуги» обусловливает специфические последствия в случае признания сделки недействительной (п. 2 ст. 167 ГК РФ) и возможность заказчика вмешиваться в осуществление деятельности исполнителя, чего нет в работах. Для заказчика здесь важна сама операция.

В связи с вышесказанным считаем, что в случае наличия стойкого овеществленного результата, полученного в итоге деятельности одного лица в интересах другого лица, необходимо говорить о «работе», а не об «услуге». Следовательно, отношения, возникающие в связи с проведением ремонта вещи, долж- ны квалифицироваться как отношения подрядного типа.

По общему правилу недостижение эффекта не влияет на исполнение обязательства по оказанию услуг. Стороны могут только желать достижения эффекта, а будет он достигнут или нет - часто не зависит от их воли, то есть в данном случае говорят о негарантированности результата услуги. Услуга, будучи объектом гражданских прав, гражданско-правовых сделок, должна отвечать требованиям фактической и юридической осуществимости. Презумпция негарантированности нематериального результата услуги в сфере осуществления профессиональной деятельности не соответствует цели всей экономической деятельности. Нормативно-правовая модель договора возмездного оказания услуг должна, на наш взгляд, предполагать существование и таких обязательств, где профессиональный услугодатель берет на себя обязательство по достижению конкретного нематериального результата. Причем достижение этого результата должно включаться в предмет обязательственного правоотношения. В то же самое время необходимо учитывать, что достижение полезного эффекта услуги зависит от того, как происходит ее потребление, имеются ли объективные условия для достижения результата, то есть от качеств не только исполнителя, но и потребителя услуги.

\section{Вывод}

Проведенное исследование позволяет говорить о необходимости выделения именно совокупности признаков, отличающих услугу от работы. Результат услуги заключается прежде всего в полезном эффекте, а не в материальном результате. Кроме того, он тесно связан с самим исполнителем и потребляется заказчиком в момент предоставления услуги. По общему правилу здесь следует говорить о невозможности гарантировать достижение субъективно-полезного эффекта деятельности. Данные признаки являются общими для всех услуг, подпадающих под действие гл. 39 ГК РФ, но могут изменяться в остальных обязательствах услугового типа. 


\section{СПИСОК ЛИТЕРАТУРЫ}

1. Зайцева, Н. В. Договор по оказанию медицинских услуг : дис. ... канд. юрид. наук / Зайцева Наталья Владимировна. - Волгоград, 2004. - 186 с.

2. Обзор судебной практики Верховного Суда Российской Федерации № 3 (2018) : (утв. Президиумом Верховного Суда РФ 14.11.2018) (ред. от 26.12.2018). - Доступ из справ.-правовой системы «КонсультантПлюс» (дата обращения: 08.03.2019).

3. Постановление ФАС Восточно-Сибирского округа от 02.06.2010 по делу № А19-24103/09. Доступ из справ.-правовой системы «КонсультантПлюс» (дата обращения: 08.03.2019).

4. Постановление ФАС Поволжского округа от 31.10.2006 по делу № А65-3004/06-СГ2-3. Доступ из справ.-правовой системы «КонсультантПлюс» (дата обращения: 08.03.2019).

5. Постановление ФАС Северо-Кавказского округа от 30.03.2011 по делу № А32-14364/2010. Доступ из справ.-правовой системы «КонсультантПлюс» (дата обращения: 08.03.2019).

6. Степанов, Д. Услуги как объект гражданских прав / Д. Степанов // Российская юстиция. 2000. - № 2. - С. 16-18.

\section{REFERENCES}

1. Zaytseva N.V. Contract for the provision of medical services. Cand. jurid. sci. abs. diss. Volgograd, 2004. 186 p. (in Russian).

2. Review of the Jurisprudence of the Supreme Court of the Russian Federation № 3 (2018): (approved by the Presidium of the Supreme Court of the Russian Federation on 11/14/2018) (ed. 12/26/2018). Access from Reference Legal Sistem “Consultant Plus" (accessed 3 August 2019). (in Russian).

3. Resolution of the Federal Antimonopoly Service of the East-Siberian District of 02.06.2010 in case № A19-24103/09. Access from Reference Legal Sistem "Consultant Plus" (accessed 3 August 2019). (in Russian).

4. Resolution of the Federal Antimonopoly Service of the Volga region on October 31, 2006 in case № A653004 / 06-СГ2-3. Access from Reference Legal Sistem "Consultant Plus" (accessed 3 August 2019). (in Russian). 5. Resolution of the Federal Antimonopoly Service of the North Caucasus Region dated 30.03.2011 in case № A32-14364/2010. Access from Reference Legal Sistem "Consultant Plus" (accessed 3 August 2019). (in Russian).

6. Stepanov D. Services as an Object of Civil Rights. Russian justice, 2000, no. 2, pp. 16-18. (in Russian).

\section{Information about the Authors}

Agnessa O. Inshakova, Doctor of Sciences (Jurisprudence), Professor, Head of the Department of Civil and Private International Law, Volgograd State University, Base Department of the Scientific and Educational Center of the Russian Academy of Sciences, Prosp. Universitetsky, 100, 400062 Volgograd, Russian Federation, ainshakova@list.ru, gimchp@volsu.ru, https://orcid.org/0000-0001-8255-8160

Natalya V. Kagalnitskova, Candidate of Sciences (Jurisprudence), Associate Professor, Department of Civil and Legal Disciplines, Volgograd Institute of Management - Branch of the Russian Presidential Academy of National Economy and Public Administration, Gagarina St., 8, 400131 Volgograd, Russian Federation, lara7@bk.ru, https://orcid.org/0000-0002-2683-9424

\section{Информация об авторах}

Агнесса Олеговна Иншакова, доктор юридических наук, профессор, заведующая кафедрой гражданского и международного частного права, Волгоградский государственный университет, базовая кафедра ЮНЦ РАН, просп. Университетский, 100, 400062 г. Волгоград, Российская Федерация, ainshakova@list.ru, gimchp@volsu.ru, https://orcid.org/0000-0001-8255-8160

Наталья Владимировна Кагальницкова, кандидат юридических наук, доцент кафедры гражданско-правовых дисциплин, Волгоградский институт управления - филиал Российской академии народного хозяйства и государственной службы при Президенте РФ, ул. Гагарина, 8, 400131 г. Волгоград, Российская Федерация, lara7@bk.ru, https://orcid.org/0000-0002-2683-9424 